\author{
Abstracta Iranica \\ Abstracta Iranica Revue bibliographique pour le domaine irano-aryen \\ Volume 40-41 | 2019 \\ Comptes rendus des publications de 2017-2018
}

\title{
Reinhard Pirngruber. The Economy of Late Achaemenid and Seleucid Babylonia
}

Astrid Nunn

\section{OpenEdition}

1 Journals

\section{Édition électronique}

URL : http://journals.openedition.org/abstractairanica/48240

DOI : 10.4000/abstractairanica.48240

ISBN : 1961-960X

ISSN : 1961-960X

Éditeur :

CNRS (UMR 7528 Mondes iraniens et indiens), Éditions de l'IFRI

Référence électronique

Astrid Nunn, "Reinhard Pirngruber. The Economy of Late Achaemenid and Seleucid Babylonia ",

Abstracta Iranica [En ligne], Volume 40-41 | 2019, document 18, mis en ligne le 15 juillet 2019, consulté le 21 avril 2021. URL : http://journals.openedition.org/abstractairanica/48240 ; DOI : https://doi.org/ 10.4000/abstractairanica.48240

Ce document a été généré automatiquement le 21 avril 2021

Tous droits réservés 


\title{
Reinhard Pirngruber. The Economy of Late Achaemenid and Seleucid Babylonia
}

\author{
Astrid Nunn
}

\section{RÉFÉRENCE}

Reinhard Pirngruber. The Economy of Late Achaemenid and Seleucid Babylonia. Cambridge: Cambridge University Press, 2017, p. xiii +249

1 Cette monographie est une version revue de la thèse de doctorat soutenue à l'université d'Amsterdam sous la direction de Bert van der Spek. L'A. ne divise pas le sujet chronologiquement mais en deux "parties clef" intitulées "Structure" et "Performance". Les dates sur lesquelles reposent les conclusions proviennent essentiellement des "Astronomical diaries" (AD). Il s'agit de centaines de tablettes, datant de 650 à 60 av. J.-C., et relatant des évènements célestes, climatiques, écologiques, économiques et historiques. L'A. s'est particulièrement intéressé aux 2000 équivalences entre argent et marchandises - orge, sésame, dattes, cresson et cuscuta, laine, moutons et esclaves - qui apparaissent à partir d'environ 400 av. J.-C. et qui constituent l'un des plus grands ensembles de données économiques de toutes les sociétés préindustrielles.

2 Le laps de temps choisi ici peut être divisé en quatre périodes: "Late Achaemenid, Early Hellenistic, Early and Late Seleucid" car "each exhibits a sructural different background". Le but de l'A. n'est pas la simple description statistique des prix mais l'explication de la manière dont ils se forment et pourquoi ils deviennent une norme pour un temps défini. L'explication des prix est analytique. L'A. considère “ the overall movements of prices in terms of variations in the three major price-determining factors, namely supply, demand and amount of money in circulation" (p. 8). Ces fluctuations sont liées aux événements historiques, à d'éventuels changements 
climatiques, visibles par exemple au niveau de l'Euphrate. Mais pour éviter une explication monocausale liée à un seul événement, l'A. intègre autant d'informations que possible. Il construit un modèle pour reconstituer l'homo oeconomicus antique, tout en s'aidant des nouvelles théories de "the New Institutional Economics (NIE)" de Douglass C. North.

3 La première partie sur la "Structure" (pp. 23-90) est intitulée "Some Key Developments in First-Millennium Babylonia". Elle offre un résumé sur les transformations économiques pendant le 'long sixth century' (626-484 av. J.-C.). Celles-ci fondamentales - consistent surtout en une intensification de l'agriculture et un plus gros volume de marchandises, ce qui implique d'une part une urbanisation, elle-même liée à un accroissement démographique et, d'autre part, un plus grand nombre d'entreprises, avec en conséquence plus de taxes et plus d'argent en cours. Même si l'évolution, e.a. au début de l'ère séleucide se dirige vers plus de "marché libre", l'A. insiste sur les forces variées du marchés et va à l'encontre les idées reçues en écrivant que la monétisation existe dès le VIème s. (voir Reinhard Pirngruber, "The Value of Silver: Wages as Guides to the Standard of Living in First Millennium BC Babylonia", in Kristin Kleber, Reinhard Pirngruber (eds.). Silver, Money and Credit. A tribute to Robartus J. van der Spek On the Occasion of his $65^{\text {th }}$ Birthday. PIHANS, 128. Leiden, Nederlands Instituut voor het Nabije Oosten, 2016, 107-118. (cf. cr. AI 37-39, rubrique 3.2.2., $\mathrm{n}^{\circ}$ 64).

Les facteurs de la production - terre, travail et capital - sont passés en revue dans le chapitre 3. La famille Murašû, par exemple, possédait des domaines étendus, mais aussi des esclaves, des moyens de production et de l'argent. Il s'agit ici d'un "interlinked market", qui se joue à un niveau régional tout en ayant éventuellement plus d'impact sur l'économie de toute la Babylonie que des facteurs extérieurs. D'une manière générale, la propriété privée était importante ce qui incite l'A. à une réflexion sur les relations entre le "privé" et "l'étatique" des temples et des rois. Le chapitre 4 "Price Volatility and Storage" relate des stratégies pour garantir une certaine stabilité des prix.

5 La seconde partie "Performance" (pp. 91-209) commence avec "A Price History of Babylonia, c. 400 - c. 140", un chapitre tout à fait concret, dans la mesure où l'A. analyse sur la base des AD les grandes lignes dans les prix, ainsi que leurs déviations. À l'époque achéménide les Grands Rois disposaient de ressources considérables. Pendant la seconde partie de cette époque, les prix ont tendance à baisser, sans que l'A. puisse en définir une cause précise. La documentation augmente fortement avec la période hellénistique qui apportera une consolidation et une monétarisation.

6 Le chapitre suivant "Historical Events in a Quantitative Analysis" reprend certaines questions de manière théorique, l'impact de la guerre ou des rebellions sur les prix par exemple, en citant ensuite les exemples de la Babylonie historique.

7 En conclusion, cette monographie innovatrice, résultat d'une lecture préliminaire de milliers de tablettes, est autant un livre d'économie pratique que théorique, dans lequel l'A. nous soumet ses réflexions sur l'interaction de facteurs endogènes et exogènes dans les fluctuations de l'économie babylonienne. 


\section{AUTEURS}

\section{ASTRID NUNN}

Université de Munich 